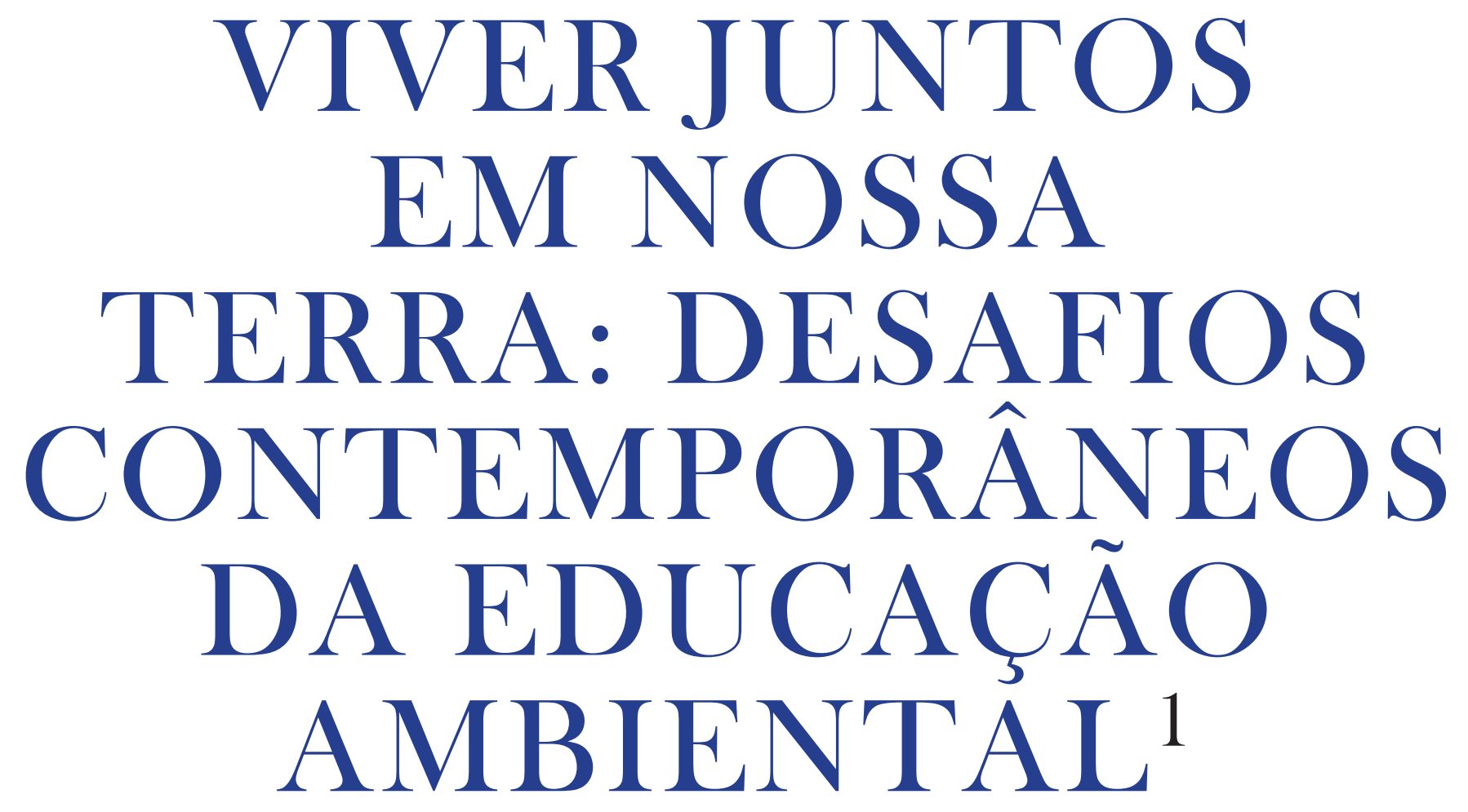

LIVING TOGETHER IN OUR LAND; THE CONTEMPORARY CHALLENGES FACING ENVIRONMENTAL EDUCATION

VIVIR JUNTOS EN NUESTRA TIERRA;

LOS DESAFÍOS CONTEMPORÁNEOS DE LA EDUCACIÓN AMBIENTAL

\title{
Lucie Sauvél
}

'Doutora em Educação pela UQÀM. Docente do Departamento de Didática e Diretora do Centro de Pesquisa em Educação e Formação relativas ao meio ambiente e à ecocidadania da Université du Québec à Montréal (UQÀM) - Montréal (Québec) Canada.

Resumo: O artigo apresenta um ensaio sobre o desafio ético e político da educação ambiental em relação ao nosso mundo fragmentado, em busca de sentido e pertencimento. As seguintes perguntas orientan a discussão: Como a educação ambiental pode contribuir na construção de nossas identidades pessoais e coletivas e melhorar assim nossa relação com o mundo? Como ela pode favorecer o compromisso com a resolução de 
problemas socioecológicos e a inovação ecossocial para a transformação de nossas sociedades? Nesse sentido, como ela pode inspirar a ação ecocidadã, baseada na democracia participativa, na justiça e na equidade ambientais? Finalmente, como pode estimular a vigilância e a crítica social com vistas a influenciar as políticas públicas relacionadas com os assuntos socioecológicos, incluindo as políticas no campo da educação?

Palavras - chaves: Educação Ambiental; Identidade Ecológica; Ecocidadania; Transformação Eco Social; Viver Juntos.

Abstract: This article presents an essay on the ethical and political challenges facing environmental education in our fragmented world, in search of meaning and belonging. The discussion is guided by the following questions: How can environmental education contribute to the construction of our personal and collective identities and improve our relationship with the world? How does it favor a commitment to the resolution of socioecological problems, and the eco-social innovation for the transformation of our societies? In this sense, how can it inspire ecological action by citizens, based on participatory democracy, in environmental justice and equity? Finally, how can it stimulate vigilance and social criticism aimed at influencing public policies related to socio-ecological affairs, including policies in the field of education?

Keywords: Environmetnal Education; Ecological Identify; Eco-citizenship; Eco-Social Transformation; Living together. 
Resumen: Este artículo presenta un ensayo sobre el desafío ético y político de la educación ambiental en relación con nuestro mundo fragmentado, en busca de sentido y pertenencia. Las siguientes preguntas orientan la discusión: ¿Cómo puede contribuir la educación ambiental a la construcción de nuestras identidades personales y colectivas, y de esa forma mejorar nuestra relación con el mundo? ¿Cómo se puede fomentar el compromiso con la solución de los problemas sociales y ecológicos y la innovación ecosocial para la transformación de nuestras sociedades? En ese sentido, ¿cómo puede la educación ambiental inspirar la acción ecociudadana, basada en la democracia participativa, la justicia y la equidad ambiental? Por último, ¿cómo puede ella estimular la vigilancia y la crítica social con el fin de influir en las políticas públicas relacionadas con temas ambientales, sociales, incluidas las políticas en materia de educación?

Palabras clave: Educación Ambiental; Identidad Ecológica; Ecociudadanía; Transformación Ecosocial; Vivir juntos.

V iver juntos em nossa Terra é certamente o desafio ético e político mais exigente e mais fundamental de nossas sociedades urbanizadas em processo de miscigenação, em que se forjam novas identidades por meio de novos relatos de alteridade. Em conexão com uma educação para a cidadania, preocupada com a democracia participativa de justiça e equidade social, é feito um chamado à educação ambiental: respirar, beber, nutrir-se, vestir-se, abrigar-se, produzir e consumir, afirmar-se, sonhar e criar... são indissociáveis de uma certa relação com o lugar e se inscrevem na trama de uma vida compartilhada, em uma rede de interações no seio dos ecossistemas dos quais somos parte integrante.

A educação ambiental nos desafia em torno de questões vivas; ela responde às inquietudes maiores. Ela nos faz aprender a reabitar coletivamente nossos meios de vida, de modo responsável, em função de valores constantemente 
esclarecidos e afirmados: aprender a viver juntos - entre nós, humanos, e também com outras formas de vida que compartilham e compõem nosso meio ambiente. De uma cultura do consumismo e da acumulação, impulsionada por ideias préfabricadas, ela pode nos levar a uma cultura do pertencimento, do engajamento crítico, da resistência, da resiliência e da solidariedade.

Nós somos seres encarnados, situados, enraizados... ou buscando raízes. Viver - esta dinâmica de ser - implica um espaço-tempo atualizado em um "aqui e agora", e reporta ao traço de nossas residências e itinerários anteriores. "Aqui", é a bolha da casa, da vila, do bairro, do país. "Aqui" se desenrola também como um fio ao longo das vias de transporte sempre mais rápidas e que se distribuem nas diversas paisagens ao longo de nossas migrações. "Aqui" toma agora a forma esférica de nossa pequena Terra. "Aqui", é onde nós estamos, em residência ou de passagem, este é o nosso fim no mundo. E sempre, o "aqui" ancorado em uma realidade concreta, é o que nós tendemos a esquecer no universo autista de nossas vidas artificializadas.

Assim, "ser humano" corresponde essencialmente a uma aventura coletiva: nós construímos nossas identidades na relação com o outro; nosso meio ambiente se constroe na junção entre natureza e cultura. Aprender a ser, isto é, viver "aqui", juntos, se reporta ao coração de um projeto de educação global, apto a estimular a resiliência social, por meio das convulsões de nosso tempo. Este artigo tem por finalidade explorar o papel da educação ambiental em um tal projeto educativo visando superar o desafio de "Viver juntos em nossa Terra".

A educação ambiental concerne mais especificamente de uma das três esferas de interação à base do desenvolvimento pessoal e social: em estreita conexão com a relação a si mesmo (esfera de construção da identidade) e aos outros (esfera de relação de alteridade humana), está em relação com o oükos, este espaço de vida compartida que associa o humano com outras formas de vida. Esta esfera de interação faz um chamado à educação ecológica: aprender a definir o seu nicho ecológico humano em conjunto com os nichos de nosso ecossistema de pertencimento - a dimensão de proximidade como a escala biosférica - e a ocupar esta função adequadamente, de modo responsável. Ela faz ainda um chamado à educação econômica: aprender a utilizar responsavelmente os recursos de nossa casa de vida comun, a compartilhar tudo solidariamente. A educação ecosófica intervém igualmente de modo transversal por clarificar sua 
própria cosmologia (uma visão de mundo em geral, uma visão de "seu" mundo mais imediato também) e para construir uma ética - com toda coerência, e que implica, entre outros, repensar o contexto da significação dos valores de "responsabilidade" e de "solidariedade".

Em nível pessoal, a educação ambiental visa construir uma "identidade" ambiental para dar significado ao nosso ser no mundo, para desenvolver um pertencimento ao meio de vida e a promover uma cultura do engajamento. $\mathrm{Na}$ escala das comunidades, seguindo aquelas de redes mais amplas de solidariedade, ela visa induzir dinâmicas sociais que favorecem a abordagem colaborativa e crítica das realidades socioecológicas e estimula as mudanças autônomas e criativas dos problemas que se apresentam e dos projetos que emergem. Para a educação ambiental é de ordem fundamental: a relação com o meio ambiente advinda de um projeto pessoal e social de construção de si mesmo e ao mesmo tempo de reconstrução do mundo pela significação e pelo agir.

No âmbito da ecoeducação, o meio ambiente não é concebido somente como um objeto de estudos ou como um tema a ser tratado entre outros; ele não é mais a constrangedora obrigação de um desenvolvimento que nós desejamos sustentável. A trama do meio ambiente é a da rede da vida nela mesma, na junção entre a natureza e a cultura. É no meio ambiente que se forja nossa identidade, nossas relações de alteridade, nossa relação com o mundo como seres de natureza, vivendo entre os vivos. Para além de uma educação "com o objetivo de, na, em, para ou pelo" meio ambiente, o objeto da educação ambiental é essencialmente nossa relação com o meio ambiente.

Em uma visão mais ampla da educação ambiental, três grandes questões se apresentam: na perspectiva de melhor "viver juntos em nossa Terra", como a educação ambiental poderia...

\section{- Enriquecer o sentido de nossas vidas?}

Como ela pode contribuir na construção de nossas identidades pessoais e coletivas? Como ela pode melhorar nossa relação com o mundo?

- Contribuir à inovação social?

Como ela pode favorecer na resolução de problemas socioecológicos e de 
ecodesenvolvimento de nossas sociedades? Como ela pode inspirar a ação cidadã?

\section{- Influenciar as políticas públicas?}

Qual é a dimensão política da educação ambiental? Como ela pode preparar os cidadãos para participar dos assuntos públicos e exercer um papel político? Para além, como as políticas públicas podem influenciar a implementação da educação ambiental?

Estas questões permitem envolver uma abordagem introspectiva no campo da educação ambiental, a fim de enriquecer os fundamentos teóricos desta dimensão, a via específica e transversal da educação: Por que educar para a relação com o meio ambiente? Como ela se constitui em uma dimensão essencial da educação fundamental? Qual é a sua contribuição a uma cidadania informada, crítica e engajada ao desenvolvimento de sociedades criativas, responsáveis e harmoniosas? Igualmente, em uma visão política, se trata de construir e de explicitar um argumento na perspectiva de favorecer a obtenção de apoio, estabelecendo estruturas e estratégias adequadas pelo pleno desenvolvimento de uma educação que leva em conta nossa relação com o meio ambiente, considerado como uma dinâmica de interações socioecológicas. Os parágrafos a seguir buscam aportar certos elementos que respondem às questões levantadas.

\section{COMO A EDUCAÇÃO AMBIENTAL PODE ENRIQUECER O SENTIDO DE NOSSAS VIDAS INDIVIDUAIS E COLETIVAS?}

A educação ambiental possui duas questões essenciais: Qual é o lugar onde eu habito, onde nós habitamos? Quem compartilha este espaço de vida - quais humanos e que outras formas de vida? De onde nós viemos? Como nós estamos reunidos neste lugar? Qual é a nossa história neste lugar? Qual é a minha história através dos diferentes lugares que forjaram minha identidade no fio de minha trajetória de vida? O que nós fazemos aqui, agora, juntos? O que nós sabemos desta casa, destas pedras, destes bosques, destes rios, destes jardins? O que nós queremos? Por quê? O que nós podemos fazer juntos? A exploração do meio de vida, a experiência dele aqui descortinam a "paisagem interior" (Dansereau, 
1973); ela pode contribuir ao reforçar a afirmação de si mesmo, individualmente e coletivamente, aqui e agora, em conexão com o pertencimento ao lugar como condição essencial do exercício de uma responsabilidade ambiental.

O meio ambiente nos forma, nos deforma, e nos transforma, tanto quanto nós o formamos, o deformamos, o transformamos. É nesta atitude de reciprocidade acolhida ou rejeitada que se apresenta nossa relação com o mundo. (Cottereau, 1999, p. 11-12).

A educação ambiental pode assim contribuir à construção de nossa identidade individual e coletiva, de nossa identidade terrena, nossa identidade de seres vivos em uma grande rede de vida compartilhada. Ela promove diversas formas de ancoragem (no lugar, no tempo, na cultura) e diversas formas de religação também. Em conexão com a identificação de nosso nicho ecológico humano, o qual devemos aprender a assumir de modo responsável, criativo e sereno, a educação ambiental nos chama para a importância da solidariedade - porque de todos os modos nós estamos ligados uns aos outros, nós os humanos e os outros seres vivos. Além da responsabilidade que está implicada, é também uma alegria para buscar, fazer vibrar nos diversos modos de nos religarmos aos seres, à vida. No coração de nossas sociedades contemporâneas, as tensões complexas entre identidade e alteridade podem encontrar uma via de equilíbrio por meio da busca de um sentido ecológico quanto à questão do "viver aqui juntos". A educação ambiental coloca em evidencia as conexões estreitas entre os valores que sustentam as relações sociais e os que regem a relação com o meio ambiente: para além do respeito, é importante desenvolver uma ética da solicitude (do cuidado) e da solidariedade, o que demanda aprender a viver juntos, COM o meio ambiente.

A perspectiva eco filosófica se desenvolve através de um processo identitário profundo que o "eu" individual não é mais delimitado pelo ego ou o organismo da pessoa. Cada um experimenta o fato de ser parte integrante da vida como um todo. (Naess, 1989, p. 174, In Tomashow, 1995, p. 21, tradução livre).

\section{COMO A EDUCAÇÃO AMBIENTAL PODE CONTRIBUIR À INOVAÇÃO SOCIAL?}

A ideia de inovação abarca tanto sobre a inovação tecnológica como a inovação cultural, econômica, legal, política... pela mudança das práticas e dos modos de vida. É uma questão, de certa forma, de inovação que concerne "as disposições dos atores que permitem colocar as problemáticas sociais de um 
modo novo e de criar dispositivos suscetíveis de encontrar novas soluções no seio da coletividade..." (Harrisson et Klein, 2007).

No intuito de contribuir para a melhoria da relação com o meio ambiente e à equidade socioecológica, a educação ambiental faz um chamado à criatividade, incita imaginar o mundo de outro modo. Ela estimula a emergência de projetos inovadores em matéria de alimentação, de energia, de gerenciamento, de habitação, de lazer... em todos os setores de nossas vidas. Ela valoriza as práticas antigas também ou aquelas culturas "marginais" ou marginalizadas. A inovação não é uma corrida precipitada ou uma fuga para outro lugar. Ela pode também restaurar e reabilitar. Neste sentido, a educação ambiental pode acompanhar e valorizar as iniciativas socioecológicas transformadoras. Um de seus papéis importantes é o de celebrar o "devir" que nos encoraja a continuar, celebrar os projetos e as realizações que nutrem a esperança, e também celebrar a inventividade e a coragem para fazer o contrário, para viver de forma diferente, para se religar de outro modo.

Mais especificamente, em uma perspectiva (eco)nômica, a educação ambiental convida a questionar a religação entre ser e ter. Demanda aprender a compartir adequadamente o espaço e os recursos comuns, a gerir suas próprias relações de consumo. Em suma, nós devemos aprender a ser guardiões, utilizadores e construtores responsáveis do Oïkos, nossa casa de vida compartilhada.

Não é a gestão do "meio ambiente" que está posta em questão, mas sim a "gestão" do nosso próprio relacionamento individual e coletivo para com o meio ambiente. Aqui a aprendizagem da desconstrução crítica encontra um terreno de larga escala. Demanda pensar criativamente e reconstruir a relação (eco)nômica para com o mundo, como uma dimensão integrante da dinâmica social, da economia endógena e solidária, contribuindo para as diversas formas de inovação socioecológica que permitem melhor viver juntos em nossa Terra: inovar para inscrever a produção e o consumo no ciclo dos processos ecológicos, inovar para melhor repartir, inovar para celebrar nossa inserção criativa neste mundo frágil, mas fascinante de diversidades e possibilidades.

\section{QUAL É A DIMENSÃO POLÍTICA DA EDUCAÇÃO AMBIENTAL?}

A educação ambiental coloca em evidência a característica essencialmente política das questões ambientais. Política significa "que concerne às coisas públicas". 
A atividade política ocorre quando os cidadãos se reúnem para discutir, debater e decidir as medidas políticas que condicionarão sua existência tanto dos habitantes de uma cidade ou de um vilarejo. (Chaia Heller, 2002, p. 216)

Ao nos convocar a dirigir um olhar crítico sobre as realidades socioecológicas, a educação ambiental pode ser um potente motor de crítica social à dimensão política. Ela convida a questionar o poder: quem decide o quê? Por quê? Em nome de quem? Ela incita a exercer uma vigília crítica, a lançar um alerta em matéria da alimentação, da água, da saúde, da usurpação de recursos... Ela estimula a participação nos debates públicos em nosso bairro, vilas, coletividades. Ela convida a denunciar, a resistir, mais ainda a criar (Aubenas et Benasayag, 2002). A educação ambiental contribui para o desenvolvimento de uma democracia participativa, na legitimação de um poder cidadão: poder fazer, poder negociar, poder convencer, poder decidir, poder transformar.

Tal educação para a ecocidadania implica a coragem de beneficiar nossos "espaços" de liberdade e fazer um chamado à responsabilidade - não se restringe a uma abordagem cívica legalista de direitos e deveres, mas de uma responsabilidade de ser, de saber e de agir, a qual implica engajamento, lucidez, autenticidade, solicitude. Ela nos convida a desconstruir ideias herdadas, lugares comuns, dogmas, "clichês".

A ideia de cidadania faz referência a este espaço de vida democrática entre pessoas livres e autônomas no seio da "cidade". O prefixo eco refere-se a Ö̈kos: se traduz aqui na cidade ecológica, que incorpora e supera a cidade humana: é a casa da vida, aquela onde estão todas as formas e sistemas de vida aos quais nós estamos intimamente conectados. A ecocidadania abre um horizonte mais global, mais holístico que a cidadania. Nós somos estes seres encravados, situados, contextualizados. Isto nos faz aprender juntos, aqui e agora, aprender a se engajar no projeto de ação reflexiva, tomando cuidado de dar significado político ao que fazemos. Politique (da raiz grega polis, corresponde à ideia de cidade) faz referência à gestão coletiva de nossos assuntos comuns e à exigência de uma democracia participativa. A ecocidadania vai para além do ecocivismo, que se limita à adoção de comportamentos individuais em função de uma moral social. Consiste em desenvolver uma cidadania consciente das linhas estreitas entre sociedade e natureza, uma cidadania crítica, competente, criativa e engajada, capaz e desejosa de participar nos debates públicos, na busca de 
soluções e na inovação ecossocial. A ecocidadania nos transporta ao plano da ética e da política, como o chamado pedagógico de Francisco Guttiérrez (2002) do Instituto Paulo Freire, para quem a educação é uma práxis política.

Política significa tomar parte face à realidade social, não ficar indiferente contra a injustiça, a violação da liberdade e dos direitos humanos, a exploração do trabalho. É descobrir a casa dos estudantes, o gosto pela liberdade de espírito. É estimular a vontade de resolver juntos os problemas, desenvolver o sentimento de ser responsável pelo seu mundo e pelo seu destino. (Gutiérrez, F. 2002).

Mas a dimensão política da educação ambiental se abre também para outra questão - outro lado: Como as instâncias políticas podem sustentar o desenvolvimento de uma educação ambiental? Sabemos bem que a educação ambiental precisa da legitimação formal, de estruturas, de estratégias de institucionalização e de meios de implementação para além dos engajamentos verbais dasvitrinespolíticas. Masela devetambémassegurarumainstitucionalização que não seja alienante, que não seja uma prescrição político-econômica imposta ao mundo da educação, que não seja um molde para pensar ou uma camisa de força. A prescrição da educação para o desenvolvimento sustentável aparece aqui como um retrocesso, uma vez que ela se inscreve na ação educativa na perspectiva estreita do advento de um mundo globalizado cuja economia artificialmente extrai a esfera social e impõe às relações entre sociedade e meio ambiente, e este último se reduz a um estoque de recursos para "gerar" modos de assegurar um maior desenvolvimento. Certamente é esta uma questão de equidade social, ainda mais em um mundo cuja economia determina as mudanças e cuja sociedade se define em termos de "capital" de produção de consumo.

Portanto, a relação com o meio ambiente não é uma questão de compromisso social - mesmo quando habilmente negociado entre certos atores sociais, em resposta à conjuntura da atual "crise de segurança". Ela não pode ser determinada por um pseudo-consenso planetário, para um programa político-econômico, verdade de certa cultura nórdica ocidental. A educação ambiental acompanha e apoia a emergência e a implementação de um projeto de melhoria de sua própria relação com o mundo, ajudando a construir significados em função das características de cada contexto em que se insere.

Fundamentada na consciência viva que a separação entre seres humanos e natureza está intimamente ligada à divisão entre os seres humanos, no seio das sociedades e entre as sociedades, a educação ambiental deve renovar 
o seu compromisso fundamental para o desenvolvimento de sociedades responsáveis, mais especificamente levando em conta as preocupações com a pobreza, o abuso de poder, a equidade inter e intra-societal, a globalização, o consumismo e a solidariedade, a responsabilidade de todas as formas de atividade humana, incluindo empreendimentos econômicos. Estimulando o exercício de uma vigília ecossocial, a educação é um espaço de liberdade para preservar, de liberdade a se reivindicar. A educação ambiental também é uma educação para a liberdade: liberdade de pensar, liberdade de olhar criticamente, de resistir, denunciar, de inovar, de se engajar.

Assim, a reflexão estimulada pelas três perguntas iniciais permite colocar em evidência muitas razões para apoiar o desenvolvimento de uma educação ambiental e de contribuir ativamente.

\section{REFERÊNCIAS}

AUBENAS F, BENASAYAG M. (2002). Résister, c'est créer. Paris: La Découverte.

COTTEREAU D. Chemins de l'imaginaire. Pédagogie de l'imaginaire et éducation à l'environnement. La Caunette: Babio, 1999.

DANSEREAU P. La Terre des hommes et le paysage intérieur. Montréal: Lemeac, 1973.

Gutiérrez, F. Educación como praxis política. México: Siglo XXI, 2002.

HARRISSON D, KLEIN JL. Introduction. In KLEIN JL, HARRISSON D. L'innovation sociale - Émergence et effets sur la transformation des sociétés. (p. 1-14). Québec: Presses de I'Université du Québec, 2007.

HELLER C. Ecology of everyday life: Rethinking the desire for nature. Montréal: Black Rose Books, 1999.

NAESS A. Ecology, community and lifestyle. New York: Cambridge University Press, 1989.

SAUVÉ L. Vivre ensemble, sur Terre - Enjeux contemporains d'une éducation relative à l'environnement. Numéro thématique. Texte liminaire. Éducation et Francophonie. Revue de l'Association Canadienne d'éducation de langue française, Vol 37, No 2, Automne 2009, p. 1 à 10, 2009.

THOMASHOW, M. Ecological identity: Becoming a reflective environmentalist. Cambridge: MIT Press, 1995. 
Artigo recebido em: 19/04/2016

Aprovado em: 31/05/2016

\section{Endereço para correspondência:}

Lucie Salvé. Centr'ERE, Pavillon Paul-Gérin-Lajoie, Université du Québec à Montréal, 1205, Rue Saint-Denis, local N-4480, Montréal, Québec, Canada, H3C 3P8. E-mail: sauve.lucie@uqam.ca

\section{NOTAS}

1 O essencial deste artigo foi extraído da seguinte publicação: Sauvé, L. (2009). Vivre ensemble, sur Terre - Enjeux contemporains d'une éducation relative à I'environnement. Numéro thématique. Texte liminaire. Éducation et Francophonie. Revue de I'Association Canadienne d'éducation de langue française, Vol 37, No 2, Automne 2009, p. 1 à 10. Tradução do artigo: Zemilda do Carmo Weber do Nacimento dos Santos. (Nota da autora). 